\title{
Perforated pyometra misdiagnosed as generalized peritonitis caused by an ileal perforation
}

\author{
Seokyoun Lee', Junhee Lee ${ }^{2}$, Nurhee Hong ${ }^{3}$ \\ Departments of ${ }^{1}$ Surgery, ${ }^{2}$ Emergency Medicine, and ${ }^{3}$ Radiology, Wonkwang University Sanbon Hospital, \\ Wonkwang University School of Medicine, Gunpo, Korea
}

An 84-year-old female was referred to emergency department with complaints of abdominal pain, fever, and vomiting. Her medical history included hypertension. Her abdomen was distended with involuntary guarding and rigidity. Laboratory findings indicated severe sepsis. Abdominal computed tomography revealed intraperitoneal air and a cystic mass abutting the uterus (Fig. 1). A radiologist suspected generalized peritonitis secondary to gastrointestinal perforation. During emergency laparotomy, we identified the perforation with the necrotic area at the uterine fundus (Fig. 2A). No gastrointestinal perforations were observed. She underwent a supra-cervical hysterectomy. A histopathological examination of the resected specimen revealed pyometra with ischemic necrosis of the endometrium infiltrated with inflammatory cells and no malignancy (Fig. 2B). She was discharged on postoperative day 18 and advised to follow-up.

Pyometra, a rare entity, involves the collection of pus in the uterine cavity. It occurs most often in postmenopausal females and may be caused by an obstruction of the cervical canal, usually secondary to malignant cervical lesions. ' Spontaneously perforated pyometra are difficult to diagnose clinically. Misdiagnoses are common because of its rarity and non-specific symptoms. Once ruptured, an acute abdomen often develops with symptoms. However, more than 50\% of cases are asymptomatic. ${ }^{2}$ The most frequent preoperative diagnosis is generalized peritonitis secondary to gastrointestinal perforation. The confirmed diagnosis of spontaneously ruptured pyometra is made by laparotomy. ${ }^{3}$ With diffuse peritonitis, perforated pyometra should be considered in the differential diagnosis of females who present with generalized peritonitis, particularly elderly.

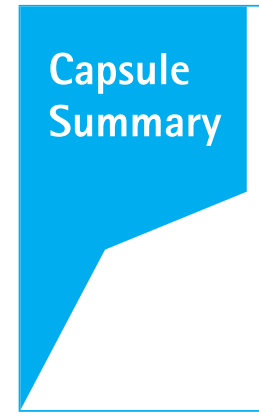

What is already known

Spontaneous perforated pyometra can present as generalized peritonitis.

What is new in the current study

Perforated pyometra should be considered in the differential diagnosis of peritonitis, especially in elderly females who present with an acute abdomen.
elSSN: 2383-4625

Received: 7 April 2020

Revised: 16 May 2020

Accepted: 25 Jun 2020

Correspondence to: Seokyoun Lee Department of Surgery, Wonkwang University Sanbon Hospital, Wonkwang University School of Medicine, 321 Sanbon-ro, Gunpo 15865, Korea E-mail: necuri@wku.ac.kr ORCID

https://orcid.org/0000-0001-7245-8449

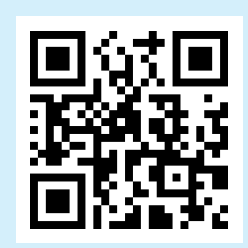

How to cite this article:

Lee S, Lee J, Hong N. Perforated pyometra misdiagnosed as generalized peritonitis caused by an ileal perforation. Clin Exp Emerg Med 2021;8(4):340-341. https://doi. org/10.15441/ceem.20.036

This is an Open Access article distributed under the terms of the Creative Commons Attribution Non-Commercial License (https:// creativecommons.org/licenses/by-nc/4.0/). 

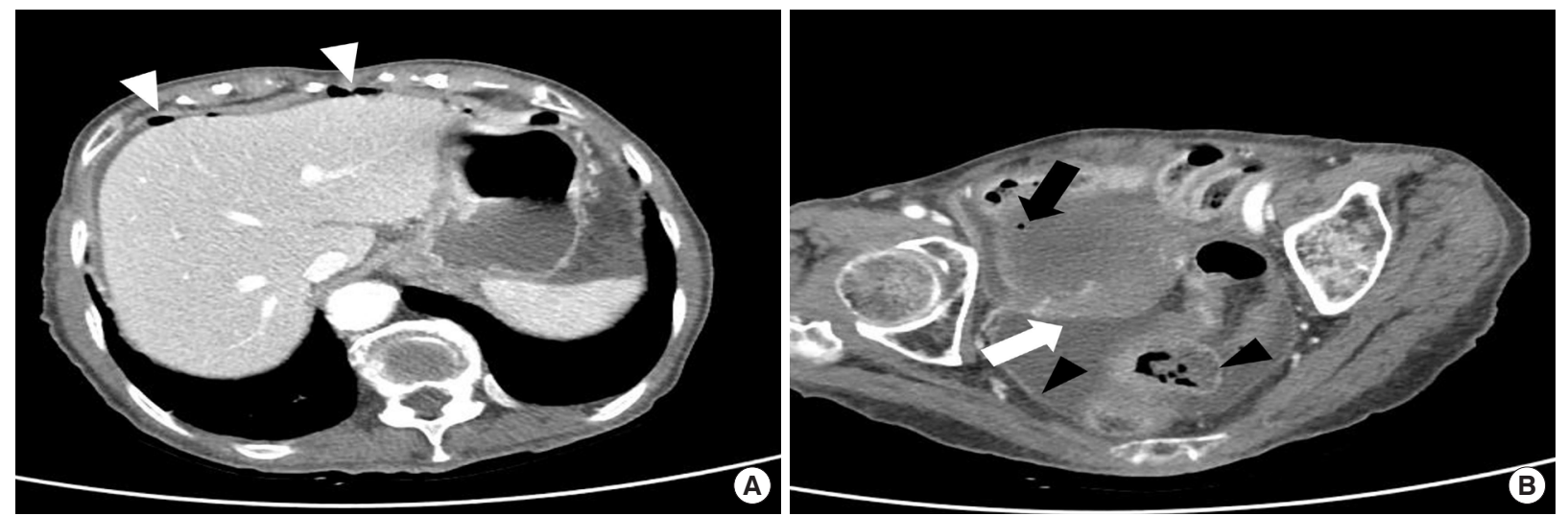

Fig. 1. (A) Axial contrast-enhanced abdominal computed tomography showing intraperitoneal free air around the peri-hepatic space (white arrowheads). (B) A 7.3-cm low-density mass is observed abutting the uterus (white arrow) on the right side of the pelvic cavity; an air-fluid level is noted (black arrow). Free non-dependent air and moderate fluid collection with smooth peritoneal enhancement are noted and suggest pneumoperitoneum (black arrowheads).
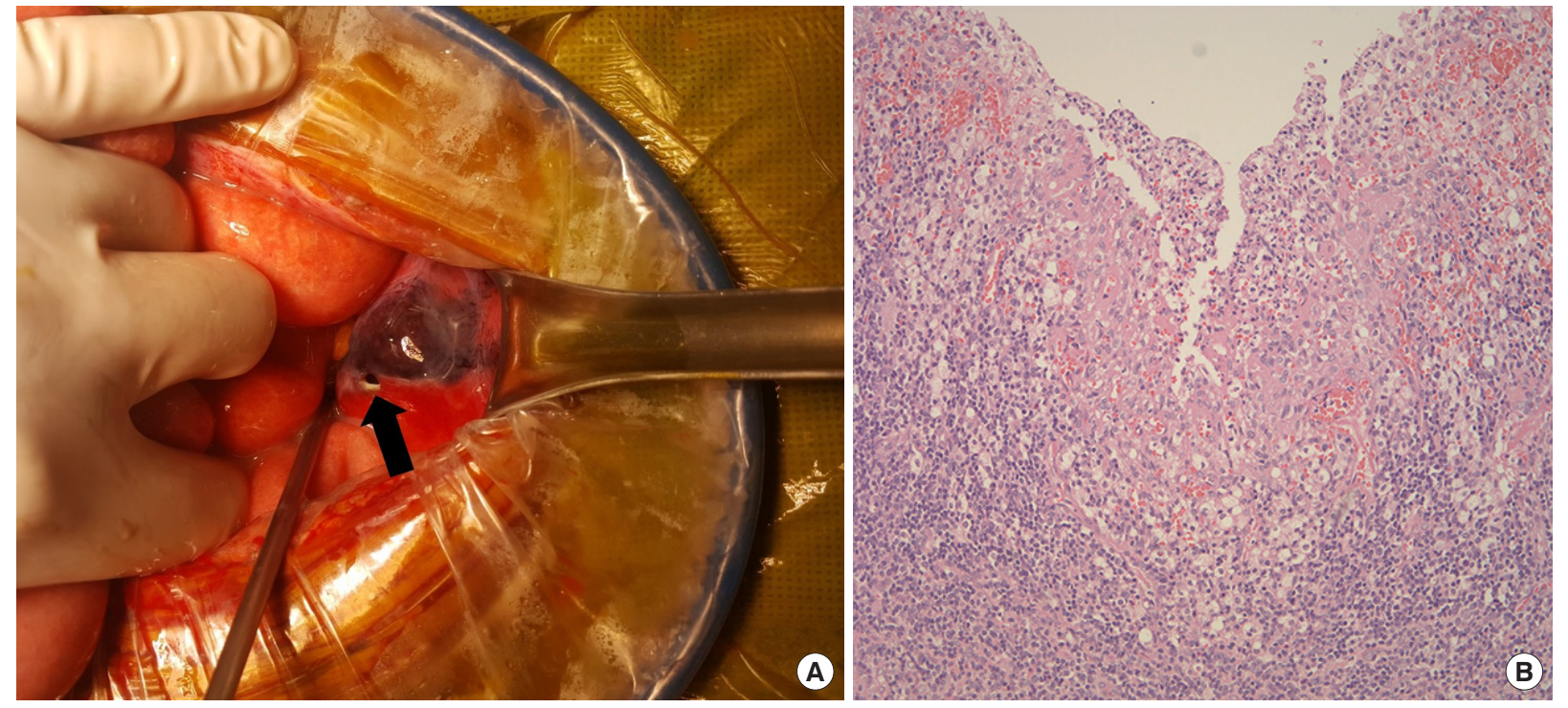

Fig. 2. (A) Intraoperative view showing a defect in the anterior wall near the uterine fundus and purulent material (black arrow) exuding from the cavity. (B) Microscopic findings of pyometra. The microphotography reveals the endometrium infiltrated with numerous inflammatory cells $\left(H \& E_{1} \times 200\right)$.

\section{CONFLICT OF INTEREST}

No potential conflict of interest relevant to this article was reported.

\section{ACKNOWLEDGMENTS}

This paper was supported by Wonkwang University in 2019.

\section{REFERENCES}

1. Chan LY, Lau TK, Wong SF, Yuen PM. Pyometra: what is its clinical significance? J Reprod Med 2001;46:952-6.

2. Nuamah NM, Hamaloglu E, Konan A. Spontaneous uterine perforation due to pyometra presenting as acute abdomen. Int J Gynaecol Obstet 2006;92:145-6.

3. Mallah F, Eftekhar T, Naghavi-Behzad M. Spontaneous rupture of pyometra. Case Rep Obstet Gynecol 2013;2013:298383. 